\title{
Mechanical, Heat-resistant, Crystallographic and Dynamical Mechanical Properties of Nylon 6/ P(N- phenylmaleimide-alt-styrene) Blends
}

\author{
Yuifei Liu', ${ }^{1,2}$ Min He ${ }^{1,2}{ }^{*}$, Daohai Zhang ${ }^{2}$, Qian Zhao ${ }^{2}$, Shuhao Qin ${ }^{1,2}$, and Jie Yu ${ }^{1,2, *}$ \\ 1 Department of Polymer Material and Engineering, College of Materials and Metallurgy, Guizhou \\ University, Guiyang 550025, China; feiliuyu1990@163.com (Y.L.); hemin851@163.com (M.H.) \\ 2 National Engineering Research Center for Compounding and Modification of Polymeric Materials, \\ Guiyang 550014, China; yujiegz@126.com (Y.Z.) \\ * Correspondence: hemin851@163.com (M.H.); yujiegz@126.com (Y.Z.)
}

\begin{abstract}
In this work, nylon 6/ P(N-phenylmaleimide-alt-styrene) blends were prepared by melt blending, and the mechanical, heat-resistant, crystallographic and dynamical mechanical properties of nylon 6/ P(N-phenylmaleimide-alt-styrene) blends with different contents were investigated and analyzed. The results showed that the mechanical properties decreased with increasing PNS, while the heat deflection temperature (HDT), relative crystallinity $\left(X_{n}\right)$, storage modulus $\left(G^{\prime}\right)$, and dynamic viscosity $(\eta)$ increased with increasing PNS. The results of differential Scanning calorimetry (DSC) proved the PNS played the positive role of nucleating PA6. And the results of dynamic mechanical analysis (DMA) proved the PNS could improve the rigidity of PA6/PNS blends. From the SEM, these PNS domains were between 0.2 and $4 \mu \mathrm{m}$ in diameter. The experimental results indicated that the addition of PNS improved the rigidity of PA6/PNS blends, and then improved the heat-resistant property.
\end{abstract}

Keywords: Heat-resistant; Nylon 6; P(N-phenylmaleimide-alt-styrene); Blends;

\section{Introduction}

Nylon 6 (PA6) is a type of typical semi-crystalline polymer material[1-3] with wide applications in aerospace, electrical equipment, and automobile industry due to its properties, such as high toughness, high rate of crystallization, and high performance. However, PA6 has a relatively low heat resistance, compared with other high performance engineering plastics, such as polycarbonate (PC), polyphenyl ether (PPO) and polyphenylene sulfide (PPS), which limits PA6's use in high-heat resistant applications such as automotive engines, fuel systems and electrical equipment. As a result, more and more researchers are interested in the research on the heat resistance of PA6. Lalit Guglani and and his co-works[4] studied the heat resistance temperature of $\mathrm{PA} 66 / \mathrm{TiO}_{2}$ composite and found that the heat deflection temperature of PA66 was increased by $5{ }^{\circ} \mathrm{C}$ by the addition of $\mathrm{TiO}_{2}$ of $6 \%$. M. Kodal and his co-works[5] studied the heat deflection temperature of PA6/Talc/Wollastonite composite and found that the heat deflection temperature of PA6 was increased by $24^{\circ} \mathrm{C}$ by the addition of 20 talc/20 wollastonite. Mária Porubskáand his co-works[6] studied the effect of electron beam irradiation on heat-resistant properties of virgin and glass fiber-reinforced polyamide 6 and found that the heat deflection temperature of PA6 was increased by $9^{\circ} \mathrm{C}$ by the effect of electron beam irradiation. Wei-Ming Peng and his co-works[7] studied the heat-resistant properties of $\mathrm{PA} 6 \mathrm{~T} / 6 / 30 \% \mathrm{GF}$ and found that the heat deflection temperature was $293^{\circ} \mathrm{C}$, but difficulty in processing. To sum up in conclusion, $\mathrm{TiO}_{2}$, Talc, wollastonite and electron beam irradiation could improve the heat resistance of PA6. But the heat resistance of PA6 was not much improved.

In addition, N-phenyl maleimide (NPMI) copolymer as the commonly used polymer heatresistant agent has been a hot topic of polymer synthesis. And their mechanism is that the pentacyclic and benzene ring rigid groups of PNS can increase the internal spin resistance of the molecular chain, and the polymer chain becomes difficult to exercise, thus improving the heat resistance of blends. In order to improve the heat resistance and compatibility of the polymer materials, A variety of NMI monomers and their copolymer are designed and synthesized. Jianting Dong and his co-works $[8,9]$ 
have synthesized N-phenyl maleimide(NPMI)-styrene(St)-maleic anhydride (MAH) (NSM) copolymer, and found that the vicat softening point, tensile strength, flexural strength, flexural modulus, and rockwell hardness of the ABS/ NSM blends were all significantly enhanced with increasing NSM content. M. Yuksel and his co-works[10] found that the glass transition temperature and thermal stabilities of the copolymers were increased by increasing the $\mathrm{N}$-substituted maleimide (N-cyclohexylmaleimide) content. Last but not the least, Shantilal Oswal and his co-works[11] have synthesized CPMI/ MMA copolymer and CPMI homopolymer, and found CPMI enhanced the initial decomposition temperature of the copolymers. This is because the incorporated five member plannar cyclic structure in the chain of copolymer enhances the thermal stability of copolymer.4 The above literature shows that $\mathrm{N}$-phenyl maleimide and its copolymers have played a positive role in improving the thermal stability and thermal stability of polymers. However, the heat resistance of nylon 6 via NPMI and their copolymers has to our knowledge not been reported. Enlightened by the above publications, we, therefore, synthesized the N-phenyl maleimide and its copolymers with styrene, in order that its copolymer could well improve the heat resistance of nylon 6 . And this work provides a direction for the heat-resistant modified fatty nylon of maleic anhydride derivatives copolymer, and lays a foundation for the subsequent design and synthesis of heat resistant agents.

In this paper, nylon 6/ $\mathrm{P}(\mathrm{N}$-phenylmaleimide-alt -styrene) (PNS) blends are prepared by the melt-impregnation process. The static and dynamic mechanical properties, heat-resistant properties, crystallographic properties, and morphologies of blends are investigated in detail. The aim of this work is to evaluate the influence and mechanism of PNS on the heat resistance of nylon 6 to investigate the feasibility to improve the heat resistance of nylon 6/ PNS blends.

\section{Materials and Methods}

\subsection{Materials}

Nylon 6 (PA6) was purchased from Yueyang petrochemical co. LTD. The P(N-phenylmaleimide-alt styrene) (PNS) was synthesized by $\mathrm{N}$-phenylmaleimide and styrene in cyclohexanone at the $100^{\circ} \mathrm{C}$, $\mathrm{BPO}$ as the initiator, via free radical copolymerization. It could be seen from supplementary materials.

\subsection{Preparation of the Samples}

PA6 and its blends were prepared by mixing PA6 and PNS in a co-rotating twin-screw extruder (TSE-40A, L/D = 40, D = 40 mm, Coperion Keya machinery, Co., Ltd., Nanjing China) at 200-240 ${ }^{\circ} \mathrm{C}$ ) with a speed of $240 \mathrm{r} / \mathrm{s}$. PA6 and its blends were dried for 24 hours at $80{ }^{\circ} \mathrm{C}$ to remove water. Then PA6 and its blends were injection moulded (type CJ80M3V,Chen De Plastics Machinery Co., Ltd., Chengde, China) at $240{ }^{\circ} \mathrm{C}$ into various specimens for testing and characterization.

\subsection{Measurements and Characterization}

\subsubsection{Mechanical Property Test}

The tensile and bending strengths of samples were carried out on a tensile tester (type WDW10C, Shanghai Hualong Testing Instrument Co., Ltd., Shanghai, China) with a speed of $100 \mathrm{~mm} / \mathrm{min}$ (GB/T 1040.1-2008). Notched Izod impact strength was measured using a pendulum impact testing machine (type ZBC-4B, Xinsansi Measurement Technology Co., Ltd., Shenzhen, China). The radius of the notch used in the specimens was $2 \mathrm{~mm}$ (GB 1043-79). All of the tests were performed at $25 \pm$ $2{ }^{\circ} \mathrm{C}$. The results were the average values of at least five specimens.

\subsubsection{Heat Deflection Temperature (HDT)}

Heat deflection temperature (HDT) measurements were performed on a thermal deformation temperature tester (USA. MTS ZWK1000). The measurements were carried out according to GB/T1634.1-2004, under a load of $0.45 \mathrm{MPa}$ and temperature rate of $120{ }^{\circ} \mathrm{C} \mathrm{h}^{-1}$. 
The DSC thermograms were carried out under nitrogen using a TA instrument Q10 for measuring non-isothermal crystallization and melting behaviours of the blends. Thermograms were recorded at a heating or cooling rate of $5{ }^{\circ} \mathrm{C} / \mathrm{min}$ in the second cycle from $40{ }^{\circ} \mathrm{C}$ to $260{ }^{\circ} \mathrm{C}$. The percent crystallinity was determined by dividing the heat of fusion value by the heat of fusion of $100 \%$ crystalline PA6 per the equation:

$$
X_{\mathrm{c}}=\frac{\Delta H_{\mathrm{m}}}{(1-\mathrm{x}) \Delta H_{\mathrm{m}}^{0}}
$$

Where $\Delta H_{\mathrm{m}}$ is crystallization enthalpy of the samples $(\mathrm{J} / \mathrm{g}), \Delta H_{\mathrm{m}}^{0}$ is the enthalpy value of the melting of a $100 \%$ crystalline form of PA6, which is $230 \mathrm{~J} / \mathrm{g}[12]$ and $\mathrm{x}$ is the weight fraction of the PNS.

\subsubsection{Morphology Observation}

Scanning electron microscopy (SEM) images were obtained on a KYKY-2800B (Beijing Branch in the Bureau of Technology Development Co., Ltd.) to investigate the impact fracture of the samples, which were etched by tetrahydrofuran for 24 hours. SEM graphs of the blends were recorded after gold coating surface treatment, with an accelerating voltage of $10 \mathrm{kV}$.

\subsubsection{Dynamic Mechanical Analysis (DMA)}

Dynamic mechanical analysis (DMA) measurements were performed on a Q800 DMA (TA Instruments, USA). The measurements were carried out at $1 \mathrm{~Hz}$ under a heating rate of $2{ }^{\circ} \mathrm{C} \mathrm{min}^{-1}$. The temperature range was from $25{ }^{\circ} \mathrm{C}$ to $120{ }^{\circ} \mathrm{C}$. and the high temperature measurements were carried out in a stream of dry $\mathrm{N}_{2}$.

\subsubsection{Dynamic Viscosity}

Dynamic viscosity were performed on advanced rheometric expansion system (ARES, TA Instrument, USA) using parallel plates mode. The measurements were conducted at $230{ }^{\circ} \mathrm{C}$. The samples were loaded onto the bottom plate of the instrument and allowed to melt. To maintain similar thermal history, each sample was heated for $4 \mathrm{~min}$ in the rheometer before testing. All tests were kept about $1.0 \mathrm{~mm}$ gap distance. The frequency sweeps at $230{ }^{\circ} \mathrm{C}$ were performed in the frequency range of $0.01 \mathrm{rad} / \mathrm{s}-500 \mathrm{rad} / \mathrm{s}$ in the linearity region. A strain of $1 \%$ was used, which was in the linear viscoelastic regime for all samples.

\section{Results and Discussion}

\subsection{Mechanical Properties}

The variation of the mechanical properties of PA6/PNS blends with different contents are displayed in Figure 1. From Figure 1, the tensile strength, bending modulus and impact toughness of PA6/ PNS blends, decrease with increasing PNS. The tensile strength of PA6/PNS blends (10\%, 15\%, and $20 \%$ ) is decreased by $3.5 \%, 15.2 \%$ and $15.2 \%$, compared with that of pure PA6 specimens. The bending modulus of PA6/PNS blends (5\%, 10\%, and 20\%) is decreased by $4.4 \%, 5.3 \%$ and $19.6 \%$, compared with that of pure PA6 specimens. The impact toughness of PA6/PNS blends (5\%, 10\%, 15\% and $20 \%$ ) is decreased by $8.4 \%, 15.5 \% 19.7 \%$ and $33.8 \%$, compared with that of pure PA6 specimens. These results indicate that the mechanical properties decrease slightly with a small amount of PNS, but decrease obviously over $15 \%$ of PNS. It has been reported that heat-resistant copolymer of Nphenyl-maleimide (NPMI)-styrene (St)-maleic anhydride (MAH) could reinforce the mechanical properties of ABS[9]. Compared with those composites, the performance of PA6/PNS blends shows a distinct difference in the mechanical properties. Combining the following analysis with the electron microscope, due to its poor compatibility with PA matrix, phase separation during blending results in poor mechanical properties[8]. It can be seen from scanning electron micrograph ( SEM) of PA6/ 
blends. PNS forms spherical domains uniformly dispersed in the PA6 matrix and the two-phase interface is clear.This is because that PNS is a non-reactive heat resistant agent and the compatibility with PA matrix is poor.

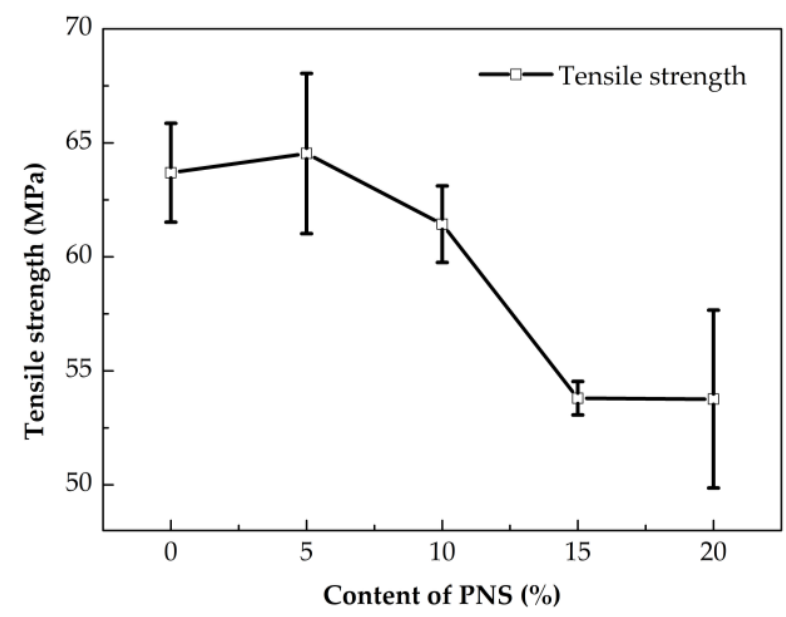

(a)

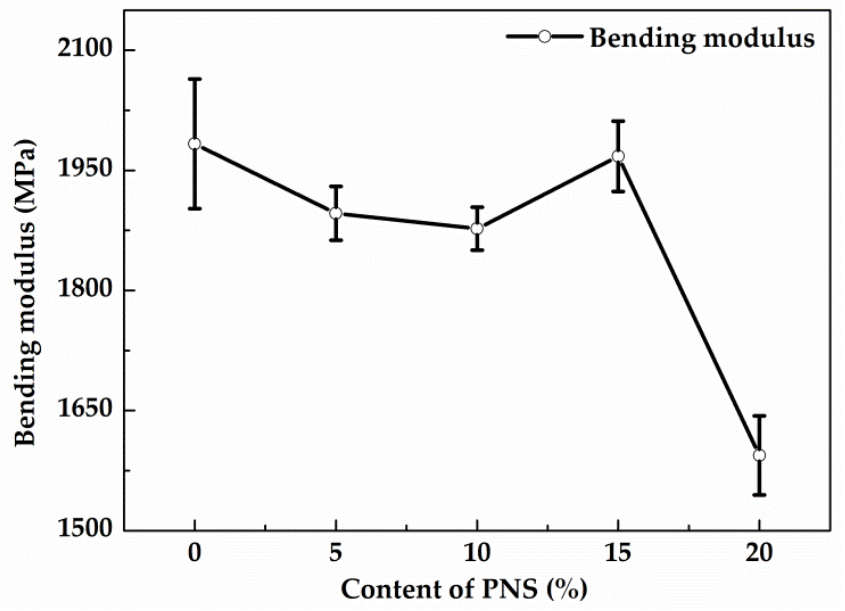

(b)

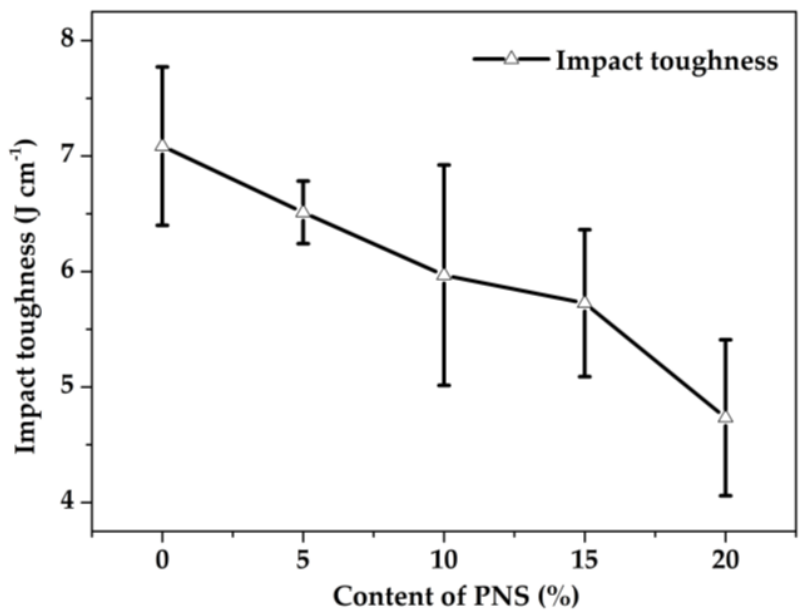

(c) 
Figure 1. Mechanical properties with different contents of PNS for virgin PA6 and PA6/PNS blends: (a) tensile strength; (b) Bending modulus; (c) Impact toughness

\subsection{Heat-resistant Properties}

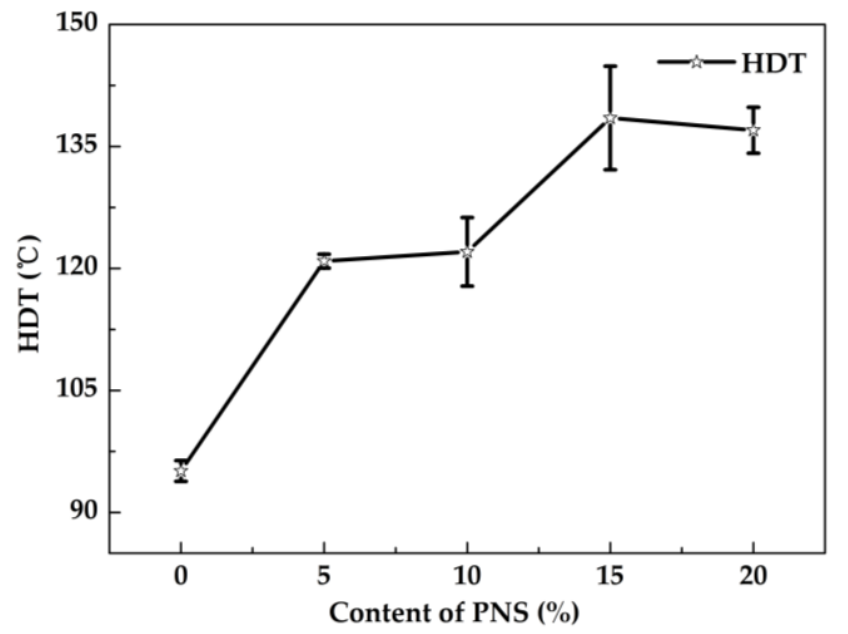

Figure 2 Heat deflection temperature with different contents of PNS for virgin PA6 and PA6/PNS blends

Heat deflection temperature (HDT) is a widely employed parameter for quality control and material development in industry. It could be taken as the material's ultimate use point[13]. The measurement of HDT is shown Figure 2. The HDT of PA6/ PNS blends increase obviously with increasing PNS. The HDT of PA6/PNS blends (5\%, 10\% and 20\%) is increased by $27.2 \%, 28.4 \%$ and $44.1 \%$, compared with that of pure PA6 specimens. These results indicate that the HDT of PA6 was increased obviously by PNS. It has been reported that copolymer of N-phenyl-maleimide (NPMI)styrene (St)-maleic anhydride (MAH)-alpha methyl styrene could reinforce the HDT of ABS[14]. Compared with those composites, the performance of PA6/PNS blends shows no difference in the heat-resistant properties. Many researchers have reported an NPMI-St copolymer with alternative chain structure with a $\mathrm{T}_{\mathrm{g}}$ as high as $230.0{ }^{\circ} \mathrm{C}[15-17]$. The polymer chain contains a five-membered planar ring and a strong polar carbonyl group; these hinder the rotation of the backbone chain and result in greater structural stiffness and higher heat-resistant properties[9]. In order to study the heat resistant mechanism, in following, crystallization properties, morphology observation and dynamic mechanical properties were characterized.

\subsection{Crystallization Properties}

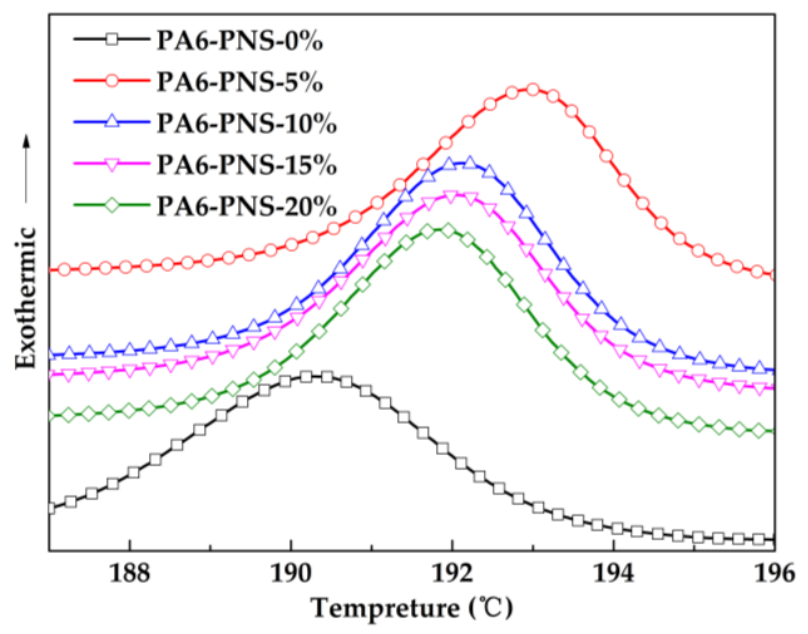


(a)

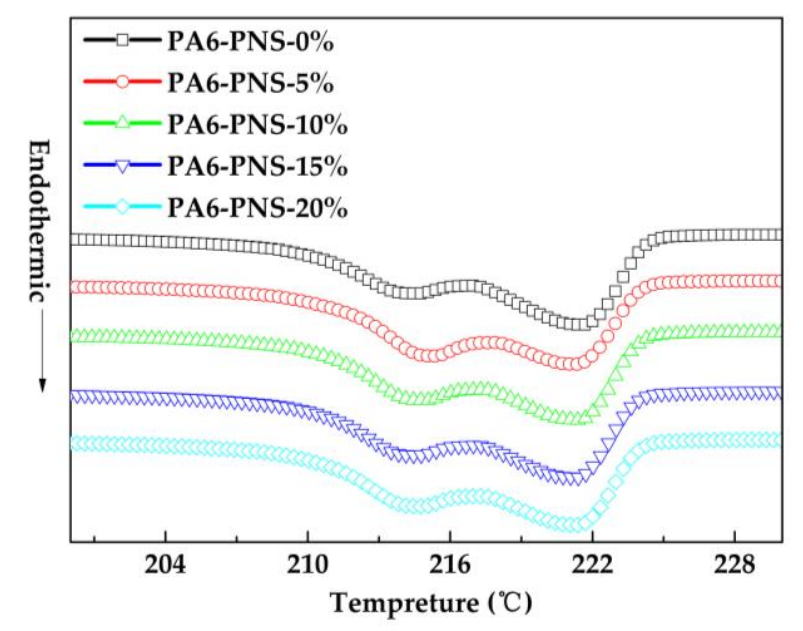

(b)

Figure 3 DSC curves with different contents of PNS for virgin PA6 and PA6/PNS blends: (a) crystallization; (b) melting.

Table 1. DSC results of PA6/PNS blends with different contents of PNS

\begin{tabular}{ccccccc}
\hline Samples & $X_{\mathrm{n}}(\%)$ & $T_{0}\left({ }^{\circ} \mathrm{C}\right)$ & $\begin{array}{c}T_{\mathrm{p}}\left({ }^{\circ} \mathrm{C}\right. \\
)\end{array}$ & $\begin{array}{c}T_{0}-T_{\mathrm{p}}( \\
\left.{ }^{\circ} \mathrm{C}\right)\end{array}$ & $\begin{array}{c}T_{\mathrm{m} 1}\left({ }^{\circ} \mathrm{C}\right. \\
)\end{array}$ & $\begin{array}{c}T_{\mathrm{m} 2}\left({ }^{\circ} \mathrm{C}\right. \\
)\end{array}$ \\
\hline 0\%PNS & 23.05 & 195.68 & 190.32 & 5.36 & 214.30 & 221.62 \\
$5 \%$ PNS & 23.00 & 197.53 & 192.94 & 4.59 & 215.37 & 221.35 \\
$10 \%$ PNS & 23.88 & 196.76 & 192.15 & 4.61 & 214.84 & 221.23 \\
$15 \%$ PNS & 26.19 & 196.19 & 191.82 & 4.37 & 214.57 & 221.50 \\
20\% PNS & 29.15 & 196.44 & 192.04 & 4.4 & 214.60 & 221.20 \\
\hline
\end{tabular}

Figure 3 (a), it is observed that the peaks change in the crystallization curves with different contents of PNS. Figure 3 (b) shows melting curves, which is used to calculate relative crystallinity (Xn.). It can be seen from Figure 3 (a) that plain PA6 has a single peak at about $190.3{ }^{\circ} \mathrm{C}$, whereas PA6/PNS blends are at about $192{ }^{\circ} \mathrm{C}$ or above. The specific onset crystallization temperature $\left(T_{0}\right)$ and crystallization peak temperature $\left(T_{\mathrm{c} 1}\right.$ and $\left.T_{\mathrm{c} 2}\right)$ are shown in Table 1 . The two peaks represent different crystal types, the low temperature peak represents the melting peak of the $\gamma$ crystal type, and the high temperature peak represents the melting peak of the $\alpha$ crystal type. PNS can induce the transformation of the $\alpha$ crystal type to the $\gamma$ crystal type. $X_{n}$ increase obviously with increasing PNS and $T_{0}-T_{\mathrm{c}}$ decrease slightly with increasing PNS. Those demonstrate that PNS play the positive role of nucleating PA6. As is known to all, crystallization can improve heat resistance of polymer[18]. Therefore, PNS as the heterogeneous nucleating agent promote nylon 6 crystal, which is one of the reasons why PNS can be as heat-resistant to modify nylon 6 .

\subsection{Morphology Observation}




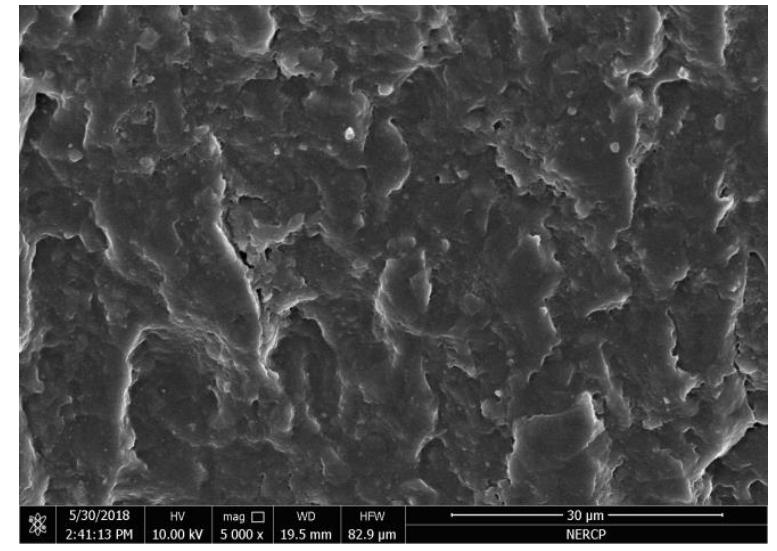

(a)

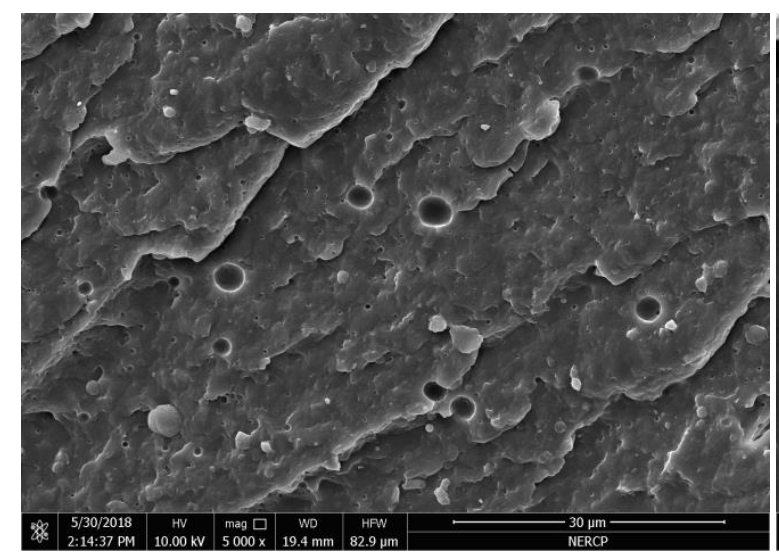

(b)

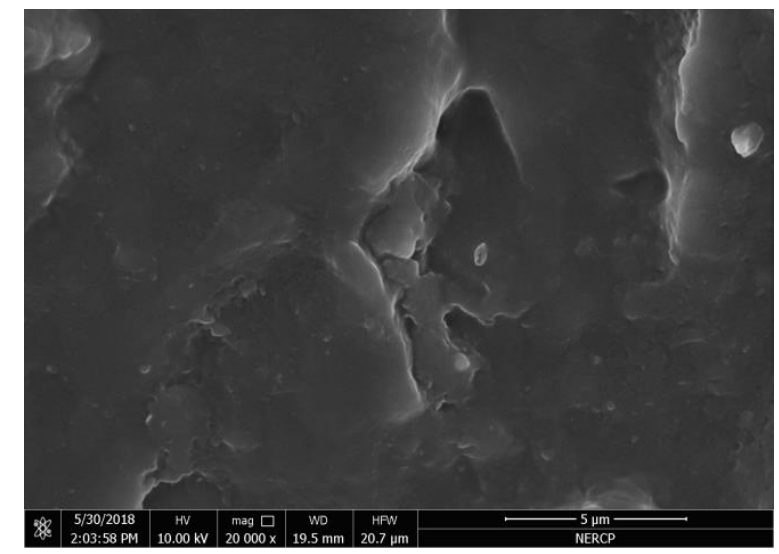

$\left(a^{\prime}\right)$

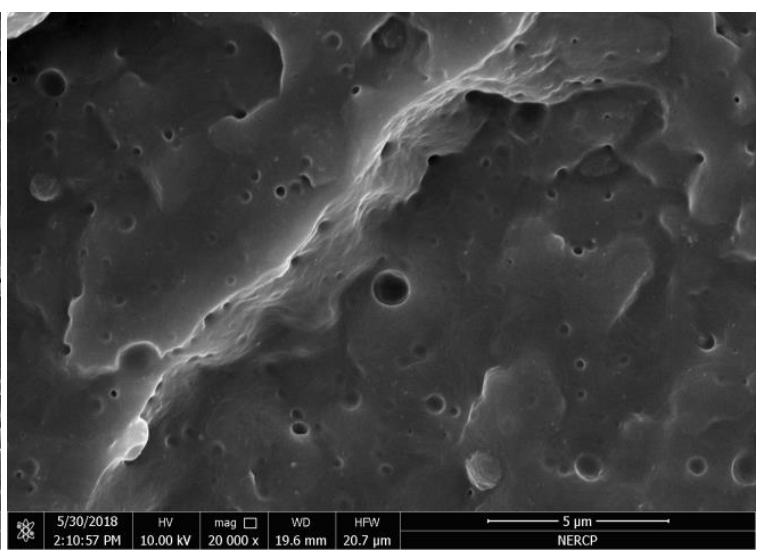

$\left(b^{\prime}\right)$

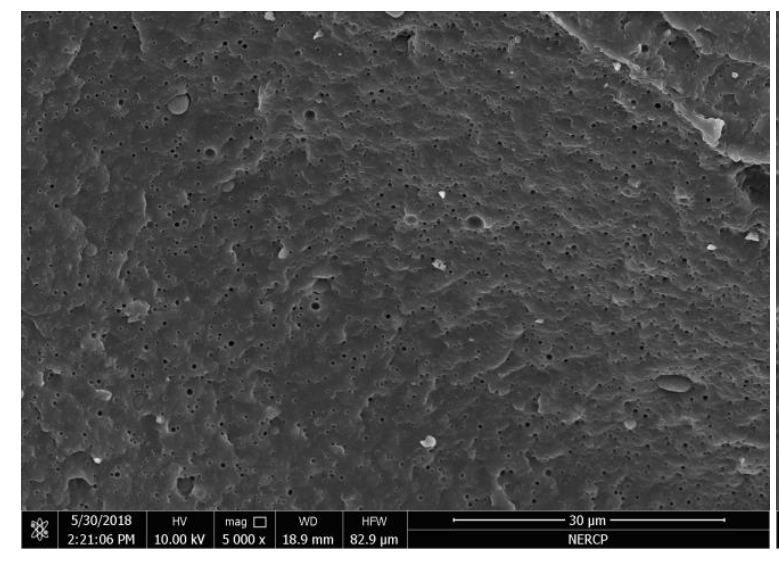

(c)

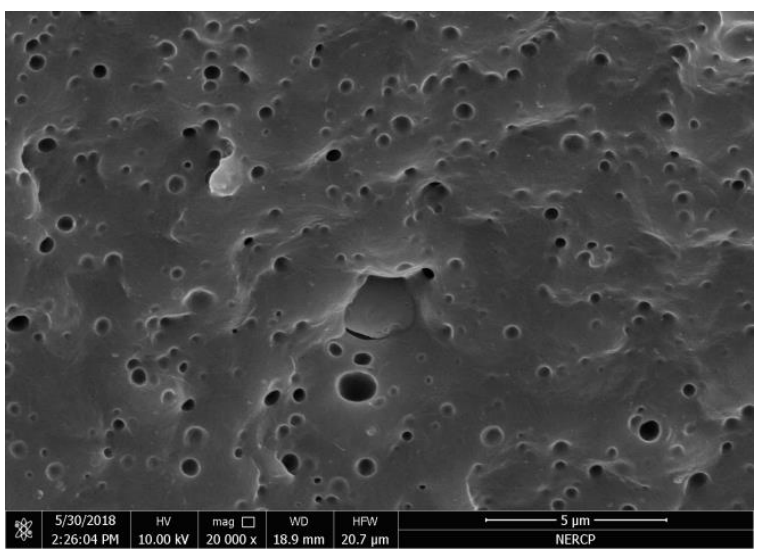

(c') 


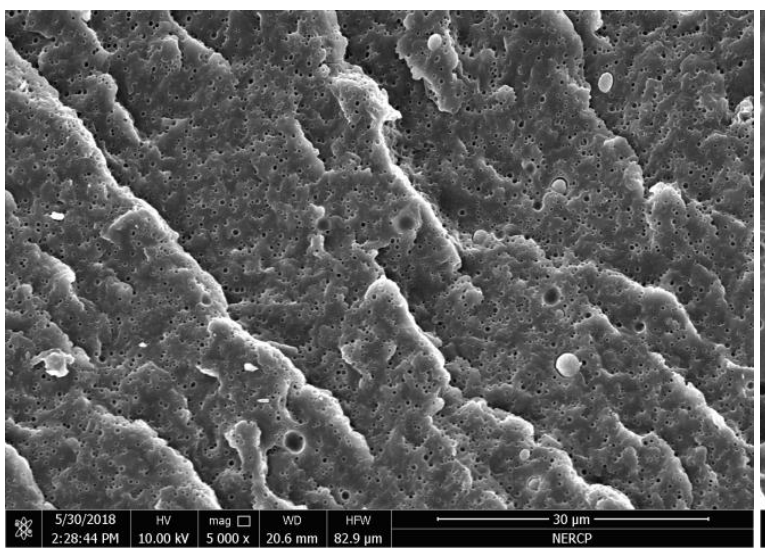

(d)

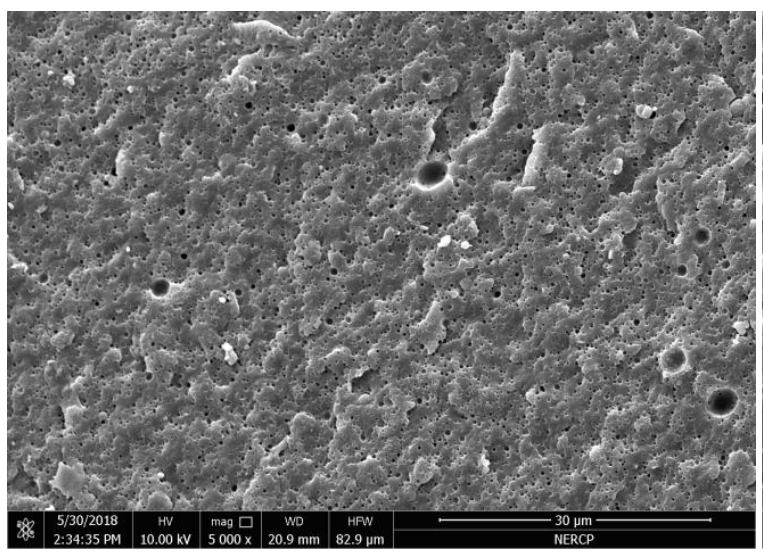

(e)

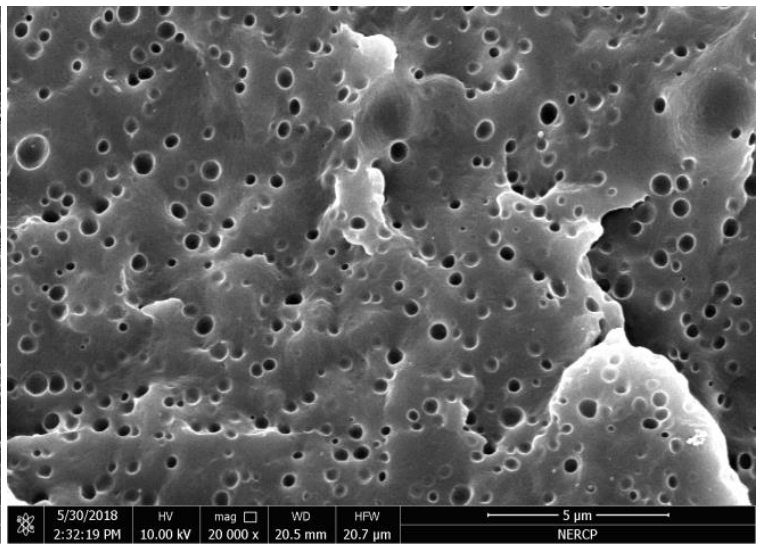

$\left(d^{\prime}\right)$

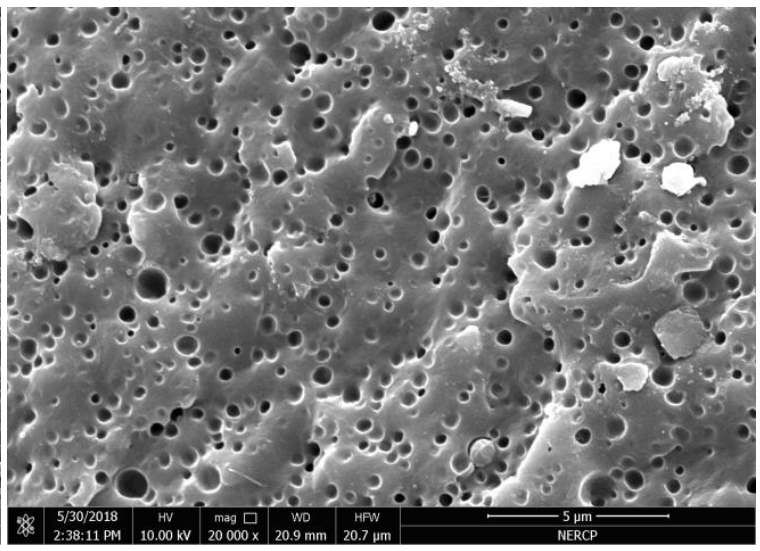

$\left(\mathbf{e}^{\prime}\right)$

Figure 4 Morphology $(5000 \times$ and $20000 \times)$ of PA6/PNS blends with different contents: $\left(a\right.$ and $\left.a^{\prime}\right)$ PNS 0\%; (b and $\left.b^{\prime}\right)$ PNS 5\%;(c and $\left.c^{\prime}\right)$ PNS 10\%;(d and d') PNS 15\%;(e and $\left.e^{\prime}\right)$ PNS 20\%;.

The morphology of the etched cut surface of the PA6/PNS binary blends are shown in Figure 4. THF was used to dissolve the PNS fraction of the blend revealing the PA6 structure. In this blend PNS forms spherical domains uniformly dispersed in the PA6 matrix and the two-phase interface is clear. This phenomenon is consistent with our previous research[19]. These PNS domains are between 0.2 and $4 \mu \mathrm{m}$ in diameter. This is due to lower viscosity of PA6 as compared to the PNS[20]. PNS spherical domains are dispersed in PA6, resulting in stress concentration. This may also explain the decline in mechanical performance.

\subsection{Dynamic Mechanical Properties}

DMA data for composites can provide the information about the storage modulus $\left(\mathrm{G}^{\prime}\right)$ and loss modulus $\left(G^{\prime \prime}\right)$ of blends to give a better observation of the phase structure and interphase mixing of the blends[21,22]. Plots of the storage modulus $\left(G^{\prime}\right)$ and loss modulus $\left(G^{\prime \prime}\right)$ as a function of temperature for PA6/PNS blends with the frequency of $5 \mathrm{~Hz}$ are displayed in Figure 5 . In Figure 5 (a), the magnitude of the G' of PA6 and PA6/PNS blends decrease approximately linearly and then become constant as a function of temperature. But in the constant stage, the $G^{\prime}$ increase with increasing PNS. This proves the PNS could improve the rigidity of PA6/PNS blends[23]. 


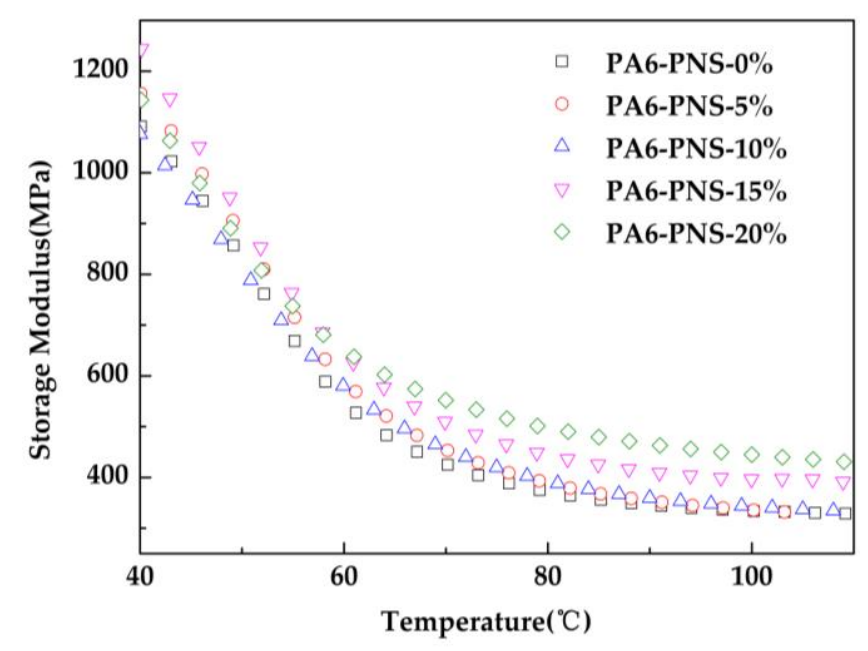

(a)

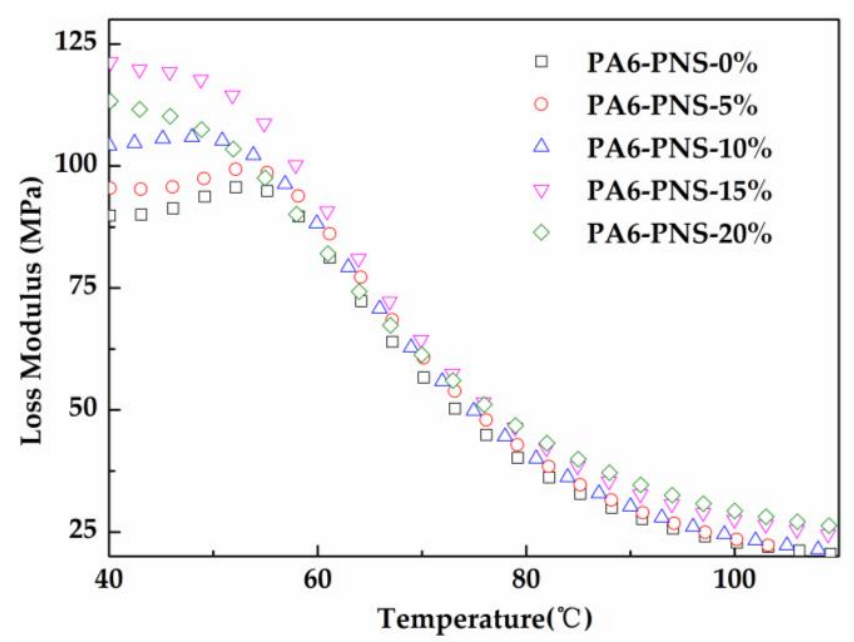

(b)

Figure 5. The DMA spectra with different temperature of virgin PA6 and PA6/PNS blends: (a) storage modulus $\left(\mathrm{G}^{\prime}\right)$; $(\mathrm{b})$ loss modulus

In Figure 5 (b), loss modulus ( $\left.G^{\prime \prime}\right)$ of PA6 and PA6/PNS blends decrease approximately linearly and then become constant as a function of temperature after $60{ }^{\circ} \mathrm{C}$. But in the constant stage, the $\mathrm{G}^{\prime \prime}$ increase with increasing PNS. This proves the addition of PNS could lead to increased internal friction of PA6 and PA6/PNS blends due to secondary motion.

3.6 Dynamic Viscosity

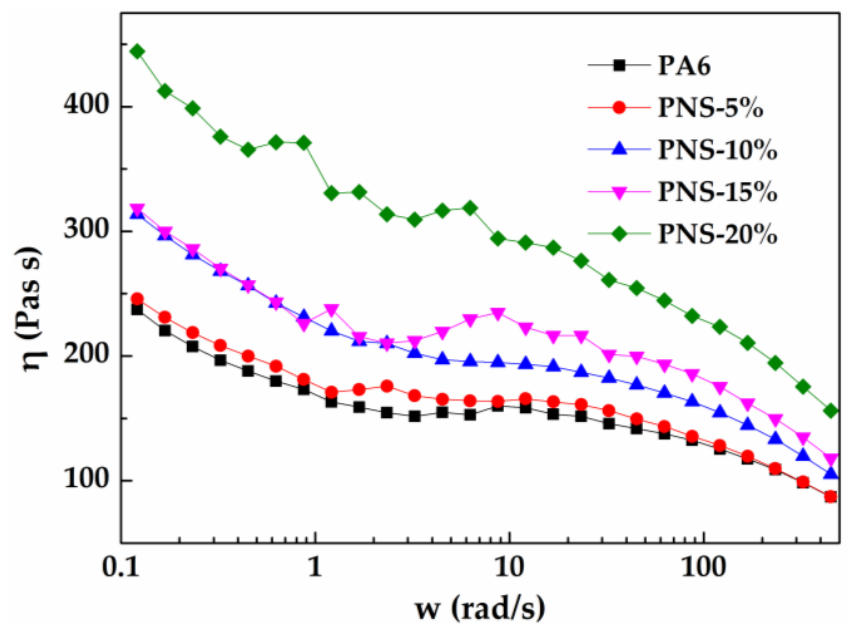

Figure 6. The dynamic viscosity with different frequencies of PA6 and PA6/PNS blends 
In Figure 6, the dynamic viscosity ( $\eta$ ) of PA6/PNS blends with different contents was showed. It can be seen that the dynamic viscosity decreased with the increase of frequency, its rheological behavior was like Newtonian fluid. And the addition of PNS improved the dynamic viscosity of PA6 blends.

\section{Conclusions}

The mechanical, heat-resistant, crystallographic, dynamical mechanical properties and SEM of nylon 6/ P(N-phenylmaleimide-alt -styrene) blends are investigated in this work. The mechanical property decreases with increasing PNS, while the heat deflection temperature (HDT), relative crystallinity $\left(X_{n}\right)$, storage modulus $\left(G^{\prime}\right)$, and dynamic viscosity $(\eta)$ increase with increasing PNS. From the SEM, these PNS domains are between 0.2 and $4 \mu \mathrm{m}$ in diameter. The experimental results indicate that the addition of PNS improve the rigidity of PA6/PNS blends, and then improve the heatresistant property.

Supplementary Materials: The following are available online at www.mdpi.com/xxx/s1, Figure $51:{ }^{1} \mathrm{H}$ and ${ }^{13} \mathrm{C}$ NMR spectra of NPMI in $\mathrm{CDCl}_{3}$, Figure S2: ${ }^{1} \mathrm{H}$ and ${ }^{13} \mathrm{C}$ NMR spectra of P(NPMI-alt-St) in DMSO, Figure S3: FTIR spectra of the synthesized NPMI and P(NPMI-alt-St).

Acknowledgments: The authors would like to acknowledge the financial support from the Natural Science Foundation of China (grant 51663006), Guizhou Province Graduate Research Foundation (KYJJ2017012), Guizhou province science and technology program project (grant [2017]5788, [2017] 5630 and [2017]1091).

Author Contributions: "Yufei Liu and Jie Yu conceived and designed the experiments; Qian Zhao and Yufei Liu performed the experiments; Daohai Zhang and Min He analyzed the data; Min He and Shuhao Qin contributed reagents/materials/analysis tools; Yufei Liu and Qian Zhao wrote the paper." Authorship must be limited to those who have contributed substantially to the work reported.

Conflicts of Interest: The authors declare no conflict of interest.

\section{References}

1. Tan H, Park SY. Crystal structure evolution of nylon 6/GOgraft nanocomposites during heat treatments and cold drawing. Polymer. 2015, 78, 111-119.

2. Xu S, Zhao X, Ye L. Mechanical and crystalline properties of monomer casting Nylon-6/Sio2 composites prepared viain situ polymerization. Polym. Eng. Sci. 2013, 53, 1809 -1822 .

3. Miri V, Elkoun S, Peurton F, Vanmansart C, Lefebvre JM, Krawczak P, et al. Crystallization Kinetics and Crystal Structure of Nylon6-Clay Nanocomposites: Combined Effects of Thermomechanical History, Clay Content, and Cooling Conditions. Macromolecules. 2008, 41, 9234-9244.

4. Guglani L, Gupta TC. Study of mechanical and tribological properties of nylon 66-titanium dioxide microcomposite. Polym. Advan. Technol. 2018, 29, 906-913.

5. Kodal M, Erturk S, Sanli S, Ozkoc G. Properties of talc/wollastonite/polyamide 6 hybrid composites. Polym. Compos. 2015, 36, 739-746.

6. Porubská M, Janigová I, Jomová K, Chodák I. The effect of electron beam irradiation on properties of virgin and glass fiber-reinforced polyamide 6. Radiat. Phys. Chem. 2014, 102, 159- 166.

7. Peng W, Tong X, Zhang M, Wang X, Zhang G, Long S, et al. Semiaromatic polyamide poly(hexamethylene terephthalamide)-co-polycaprolactam: Thermal and flame-retardant properties. J. Appl. Polym. Sci. 2018, 135, 46451.

8. Dong J, Zhao C, Tan Z, Li S, Fan Z. Structure and properties of heat-resistant ABS resins innovated by NSM random copolymer. Polym. Compos. 2013, 34,920-928.

9. Zhao C, Dong J, Li S, Fan Z. Synthesis and characterization of heat-resistant N-phenyl maleimide -styrene-maleic anhydride copolymers and application in acrylonitrile- butadiene- styrene resin. 
J. Appl. Polym. Sci. 2012, 126, 169-178.

10. M. Yuksel, T. C. Canak and I. E. Serhatli, Synthesis of liquid crystalline moiety containing Ncyclohexylmaleimide copolymers Polym. Advan. Technol., 2009, 20, 312.

11. Oswal S, Bhandari VK, Bhamore P, Malek NI. Free Radical Copolymerization of Methyl Methacrylate and Styrene with N-(4-Carboxyphenyl)maleimide. Int. J. Polym. Mater. 2007, 56, 421-435.

12. Wang $\mathrm{H}$, Huang $\mathrm{R}, \mathrm{Wu} \mathrm{D}$, Liu C, Cheng W, Xie L. Effects of thermal oxygen aging on the crystallization behavior and properties of nylon 6. Polym. Mater. Sci. Eng. 2013, 29, 88-92.

13. Wang Y, Chien C, Chiao S, Lee T. Reactive compatibilization of polyetherimide with polyamide 6,6: part 1. Effect of functionalizing polyetherimide. Polym. Bull. 2016, 73, 703-26.

14. Li Y, Li W, Qian Z, Zhang L, Dong L, Wang L. Synthesis of N-phenyl maleimide/ styrene/ methyl styrene/maleic acid tetramer and its modification to ABS resin. Polym. Mater. Sci. Eng. 2017, 33, $1-6$.

15. Lu Y, Sun W, Shen Z. Copolymerization of N-phenylmaleimide with styrene by rare earth coordination catalyst. Eur. Polym. J. 2002, 38, 1275-1279.

16. Iwatsuki S, Kubo M, Wakita M, Matsui Y, Kanoh H. Polymerization thermodynamics of Nphenylmaleimide and its copolymerizations with styrene and phenyl vinyl sulfide. Macromolecules. 1991, 24, 5009-5014.

17. Shan G, Weng Z, Huang Z, Pan Z. Free radical copolymerization and kinetic treatment of styrene with N-phenylmaleimide. J. Appl. Polym. Sci. 1997, 63, 1535-1542.

18. Tang, Z., Zhang C., Liu X., and Zhu J. The crystallization behavior and mechanical properties of polylactic acid in the presence of a crystal nucleating agent. J. Appl. Polym. Sci., 2012. 125: 11081115.

19. Zhang J, He M, Ci S, Liu D, Yu J, Lu S. Synthesis of N-phenyl maleimide - maleic anhydride and its effect on the heat resistance of nylon 6. Polym. Mater. Sci. Eng. 2015, 31, 22-26.

20. Jafari SH, P Tschke P, Stephan M, Warth H, Alberts H. Multicomponent blends based on polyamide 6 and styrenic polymers: morphology and melt rheology. Polymer. 2002, 43, 6985- 6992.

21. Zhang D, He M, He W, Zhou Y, Qin S, Yu J. Influence of Thermo-Oxidative Ageing on the Thermal and Dynamical Mechanical Properties of Long Glass Fibre-Reinforced Poly(Butylene Terephthalate) Composites Filled with DOPO. Materials. 2017, 10, 500.

22. Perera MCS, Ishiaku US, Ishak ZAM. Thermal degradation of PVC/NBR and PVC/ENR50 binary blends and PVC/ENR50/NBR ternary blends studied by DMA and solid state NMR. Polym. Degrad. Stab. 2000, 68, 393-402.

23. González-Ausejo, J., Gameza-Perez J., Balart R., and Maria Lagaron J. Effect of the addition of sepiolite on the morphology and properties of melt compounded PHBV/PLA blends. Polymer Composites, 2017. 